\title{
IS DEMOGRAPHY DESTINY? THE ROLE OF STRUCTURAL AND DEMOGRAPHIC FACTORS IN AUSTRALIA'S PAST AND FUTURE LABOUR SUPPLY
}

Jeromey B. Temple, ${ }^{\dagger}$ The Australian Demographic and Social Research Institute, The Australian National University

Peter McDonald, The Australian Demographic and Social Research Institute, The Australian National University

Following the release of the Intergenerational Report, the Australian Treasury identified the levers to address the economic effects of demographic ageing as 'the three Ps': population, participation and productivity. To date, the first ' $\mathrm{P}$ ', population, has been treated as an exogenous factor, with the common view being that there is very little that the government can do to supplant demographic ageing. Focusing upon labour supply, this paper shows how variation in Australia's underlying demography can significantly alter Australia's future labour supply. Although governments cannot redirect the cohort flow component of population ageing, much can be achieved in promoting growth of the labour supply by maintaining or increasing fertility (in the longer term), or increasing targeted migration (in the short to medium term). This paper also decomposes the relative role of cohort flow, changing demography and changing labour force participation on the growth of the labour supply over the past 20 years. Over this period, the entry of the baby boom generation (cohort flow) and increased labour force participation of women accounted for almost all of the growth in the labour force. Changing demography had very little effect. However, Australia's future labour supply will not include a large increase in cohort flow (as caused by the baby boomers) or a very large increase in female labour force participation. Regardless of the assumptions used, labour supply growth will be considerably lower in the next and subsequent 20 years, when compared to the previous 20 .

Keywords: Labour force, labour migration, labour supply, economically active population, demographic ageing, population projection

Many studies have sought to examine the economic implications of population ageing for health care financing, public pensions, superannuation and community care (Costello 2002; Dowrick and McDonald 2002; Productivity Commission 2005). The Australian government's Intergenerational Report has estimated that by 2041-42 a

\footnotetext{
${ }^{+}$Address for correspondence: The Australian Demographic and Social Research Institute, The Australian National University, Canberra ACT 0200, Australia. Email: Jeromey.Temple@anu. edu.au.
} 
fiscal gap of 5 per cent of GDP will exist, given the additional demands placed upon public resources by population ageing. Current research stresses that population ageing, rather than bringing unmanageable costs, brings issues that with appropriate policy and planning are manageable. Indeed, some of the costings made in the intergenerational report have attracted criticism due to the conservative assumptions about labour supply underlying the analysis. For example, Dowrick and McDonald (2002) argued that the report understates the effect of a fall in unemployment, underestimates the potential for increased labour force participation and overestimates the cost of future health care and aged care. Mitchell and Mosler (2003) too, argue that the report underestimates the effect of increasing employment.

Following from the Intergenerational Report, the Australian Treasury has identified the policy levers to address the economic effects of future ageing as the 3Ps: population, participation and productivity. The government argues that if the size of the economy can be boosted through increased labour market productivity and participation, then the fiscal gap occurring because of population ageing can be eliminated. However, a strong assumption is that the first $\mathrm{P}$, population, is predetermined and unchangeable. More specifically, both productivity and participation are seen as being amenable to government action through labour market, family and education and training policies, but this is not the case with population. Population is seen as exogenously given, and the labour market and economy more generally must react to the supply constraints imposed by changing demography. For example, launching the Productivity Commission report on population ageing, the then Treasurer Peter Costello, borrowing the line of eighteenth-century sociologist Auguste Comte, declared: 'Demography is Destiny. Our destiny has been set by the changing fertility rate since the 1960s, it is set in stone. We can't walk away from it, we can't change it' (Costello 2004). Similarly, the Secretary of the Department of Workplace Relations has recently stated: 'There is limited scope for the government to slow or prevent current population ageing, so the policy focus has been on productivity and participation' (Boxall 2006). Indeed, to date much of the previous research on population ageing and labour supply has focused upon adapting to certain labour force futures, rather than examining policy options aimed at determining the future labour force (Temple and McDonald 2006). That is, the underlying demographic determinants are viewed as unchangeable, a destiny to which policy makers and employers must adapt.

The purpose of this paper is to challenge these assumptions. First, we decompose the relative growth of the labour supply over the period 1980-2000 that is attributable to demographic effects, that is, changes in age distribution, fertility, mortality and migration; and to structural effects: changes in labour force participation. Secondly, we examine the contribution of structural and demographic effects in shifts in the future labour supply, from 2006 to 2051, using six assumptions about future demography and three labour force participation scenarios. We argue that, after controlling for changes in the age distribution, future demography is not destiny, particularly in the long term. In the medium to long term, variations in the underlying demography, specifically fertility, can account for about half of the growth in the labour supply. Increased participation has the potential to account for the remaining half of the growth in the labour supply. These results underscore the need for federally directed policy that incorporates a labour market policy together with a more general population policy. 


\section{Data and method}

To examine possible futures for Australia's labour supply we draw upon several publicly available data sources. Base and historical Estimated Resident Population data, along with historical life table and migration statistics, are taken from the ABS historical population statistics. Projections of labour force participation rates have been provided to the authors by the Productivity Commission, who used these rates as the basis for the report Economic Implications of an Ageing Australia.

$$
P_{i, j+1}^{y+1}=P_{i, j}^{y} S_{i, j}^{y}\left[1+M_{i j}^{y}\right], j \geq 0
$$

For age 0, [1] is simply:

$$
P_{i, 0}^{y+1}=\frac{S R_{i}}{2}\left\{\sum_{j=15}^{49}\left(b_{j}^{y} \times P_{f, j}^{y}\right)+\left(b_{j}^{y} \times A_{f, y}^{y+1}\right)\right\}\left\{s_{i, b}^{y} \times m_{i, b}^{y}\right\}
$$

Given:

$A_{i, j}^{y} \quad$ is the population of sex (i) at age (j) in year (y)

$A_{f, j}^{y}$ is the population of females at age (j) in year (y)

$b_{j}^{y} \quad$ is the age specific fertility rate

$m_{i, j}^{y}$ is the age-sex specific net migration intensity

$s_{i, j}^{y} \quad$ is the age-sex specific survival ratio

$S R_{i}$ is the survival ratio at birth for sex (i)

The projected labour supply by age and sex $\left(L S_{i, j+1}^{y+1}\right)$ is then calculated using the agesex specific participation rate $\left(P R_{i, j+1}^{y+1}\right)$ :

$$
L S_{i, j+1}^{y+1}=P_{i, j+1}^{y+1} \times P R_{i, j+1}^{y+1} \quad j \geq 15
$$

With the above data, we define a number of scenarios for the key parameters of interest: (1) the set of fertility scenarios with variations of $b_{j}^{y}$; (2) the set of mortality scenarios with variations of $s_{i, j}^{y}$; (3) the set of migration scenarios which vary $m_{i, j}^{y}$; and (4) the set of labour force participation scenarios that vary $P R_{i, j+1}^{y+1}$. Using these simple projection methods, it is also possible to create synthetic histories of the labour supply over the period 1980 to 2000 . More specifically, the reverse cohort component projection method is used to decompose the relative role of structural and demographic factors upon the labour supply over the past 20 years of Australia's labour supply.

\section{Australia's labour-supply past}

Over the past 25 years, the size of the Australian labour force increased from about 6.5 million to 10.3 million in 2005, almost 60 per cent. This massive increase has occurred for several reasons. First, the entry of the baby-boom generation as a result of high 
Table 1 Changes in underlying demographic parameters, 1980-2000

\begin{tabular}{lrr}
\hline & 1980 & 2000 \\
\hline Total fertility rate & 1.9 & 1.7 \\
Life expectancy: males & 71 & 77 \\
Life expectancy: females & 78 & 82 \\
Annual net migration & 75,941 & 107,300 \\
Population & $14,695,356$ & $19,153,380$ \\
\hline
\end{tabular}

fertility rates during the 1950s and 1960s led to a large influx of young workers. Second, over this same period of time, labour force participation rates for women have increased significantly. Third, through Australia's migration program, in particular the skilled migration program, the number of young workers has also increased. Working in the opposite direction, the movement towards early retirement for men has reduced the potential labour supply of male workers. Future decades will see a much stronger reduction in labour force growth (Productivity Commission 2005), but the important question is by how much? However, before turning to the implications of demographic and structural change in Australia's future labour supply, it is important to understand the relative importance of these changes in Australia's labour supply history.

Changes in the underlying demography affect labour supply through shifts in the supply of the working-age population, all persons aged 15-64. Between 1980 and 2000, the total fertility rate (TFR) fell from 1.9 to about 1.7 births per women. Over the same period, annual net migration (ANM) has increased from 75,900 to 107,300 and life expectancy at birth has increased by six years for males and four years for females (Table 1).

With the working-age population demographically determined, the realized labour supply is a function of the extant working-age population and structural effects that determine labour force participation rates and unemployment. Table 2 displays the labour force participation rates for men and women over the period 1980 to 2005. Results indicate important sex differentials in participation rates between 1980 and 2005. For men, participation has dropped since 1980, with one exception. Participation among those aged 65-69 increased slightly over the full period; however, participation for all other retirement age groups (ages 55 and over) decreased significantly. In contrast, the participation rates of women have experienced large gains over the same period of time. Nonetheless, participation rates remain higher for men than women, from age 20 onwards. This result is particularly pronounced during the key reproductive ages.

Given these important shifts in both demography and labour force participation, it is important to understand the flow-on effects for labour supply. Results in Figure 1 display several measures of the changes in the male and female labour supply between 1980 and 2005. In Panels A and B, the thick dark line displays the actual level of labour supply historically recorded. The 'diamond' line shows what the labour supply would have been if there had been no changes in the underlying demography and no changes in labour force participation rates, that is, it shows the effect of 
Table 2 Labour force participation rates, 1980-2005 (month of July)

\begin{tabular}{|c|c|c|c|c|c|c|c|c|}
\hline & \multicolumn{4}{|c|}{ Male LFPR } & \multicolumn{4}{|c|}{ Female LFPR } \\
\hline & 1980 & 1990 & 2000 & 2005 & 1980 & 1990 & 2000 & 2005 \\
\hline 15-19 & 64.5 & 61.8 & 58.3 & 59.0 & 59.7 & 59.8 & 60.0 & 61.4 \\
\hline $20-24$ & 91.2 & 89.7 & 86.9 & 84.8 & 70.3 & 77.9 & 77.3 & 77.5 \\
\hline $25-29$ & 95.5 & 94.4 & 91.7 & 90.3 & 52.2 & 67.8 & 71.9 & 74.9 \\
\hline $30-34$ & 96.1 & 94.9 & 92.3 & 91.7 & 50.9 & 63.6 & 66.2 & 68.8 \\
\hline $35-39$ & 96.0 & 94.1 & 91.2 & 90.9 & 56.4 & 69.5 & 68.5 & 69.4 \\
\hline $40-44$ & 95.1 & 94.1 & 91.7 & 90.0 & 59.7 & 73.3 & 73.9 & 74.7 \\
\hline $45-49$ & 93.4 & 91.8 & 89.1 & 89.0 & 53.4 & 66.1 & 74.1 & 78.2 \\
\hline $50-54$ & 90.0 & 86.6 & 84.8 & 85.4 & 42.4 & 53.0 & 65.6 & 71.0 \\
\hline $55-59$ & 82.4 & 74.9 & 72.3 & 73.3 & 27.9 & 32.3 & 46.4 & 53.6 \\
\hline $60-64$ & 53.3 & 49.9 & 46.6 & 49.6 & 12.8 & 15.1 & 20.3 & 27.7 \\
\hline $65-69$ & 17.3 & 14.1 & 18.6 & 21.3 & 5.1 & 4.6 & 8.2 & 9.1 \\
\hline $70+$ & 7.2 & 6.1 & 5.5 & 5.7 & 1.4 & 1.1 & 1.4 & 1.5 \\
\hline
\end{tabular}

'cohort flow'. Cohort flow is the effect on the labour supply of the ageing of the existing age distribution. The substantial rises due to cohort flow (Arrow 1) reflect the full entry of the baby-boom generation into the labour force ages. The large dotted line adds in the effects on labour supply of actual changes in the three demographic variables, fertility, mortality and migration, assuming labour force participation had remained constant at 1980 levels throughout this 20-year period. The effect here is positive for both men and women (Arrow 2) but is relatively small. Finally, the effects of the actual changes in labour force participation rates (Arrow 3 ) can be added in to bring us to the final, actual result represented by the thick dark line.

Figure 2 decomposes the male and female labour supply into the relative roles of cohort flow (pre-1980 demographic momentum), changing demography (post-1980), and changing labour force participation. For males, cohort flow accounted for the majority of the increase in labour supply whereas shifts in post-1980 demography accounted for less than ten per cent of the total change. Declining labour force participation accounted for about -20 per cent of the change in male labour supply of this period. In contrast, increasing participation was the major factor increasing female labour supply, accounting for about half of the total change. Cohort flow also contributed substantially to the increase in the female labour force while only a small proportion of the total change was accounted for by shifts in demography.

\section{Australia's labour-supply future}

From this historical analysis, it is clear that structural changes in the labour force (as measured by the age-sex specific labour force participation rates) and cohort flow (extant population momentum) were the driving force behind the increase in the labour supply from 1980 to 2000 . This raises the question whether these patterns persist for Australia's labour supply future. More specifically, how do changes in fertility, 
Figure 1 Numerical components of labour supply change, 1980-2000

Panel A: Components of labour supply change, males

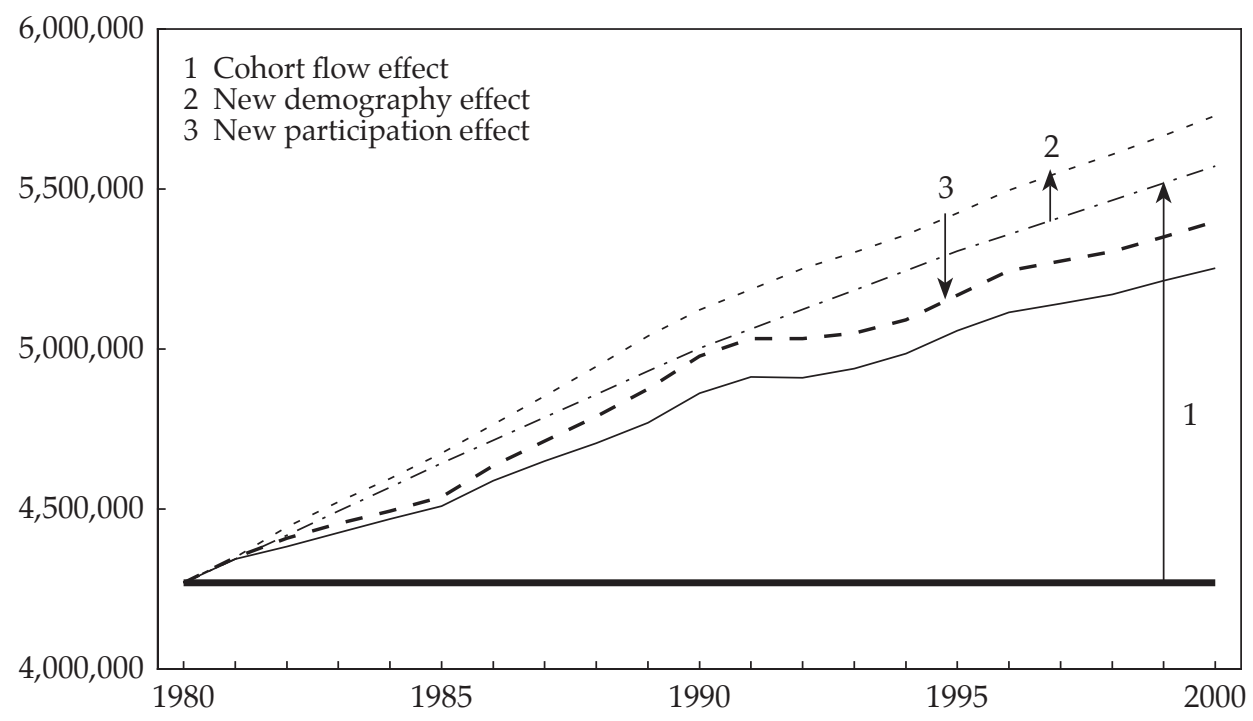

Panel B: Components of labour supply change, females

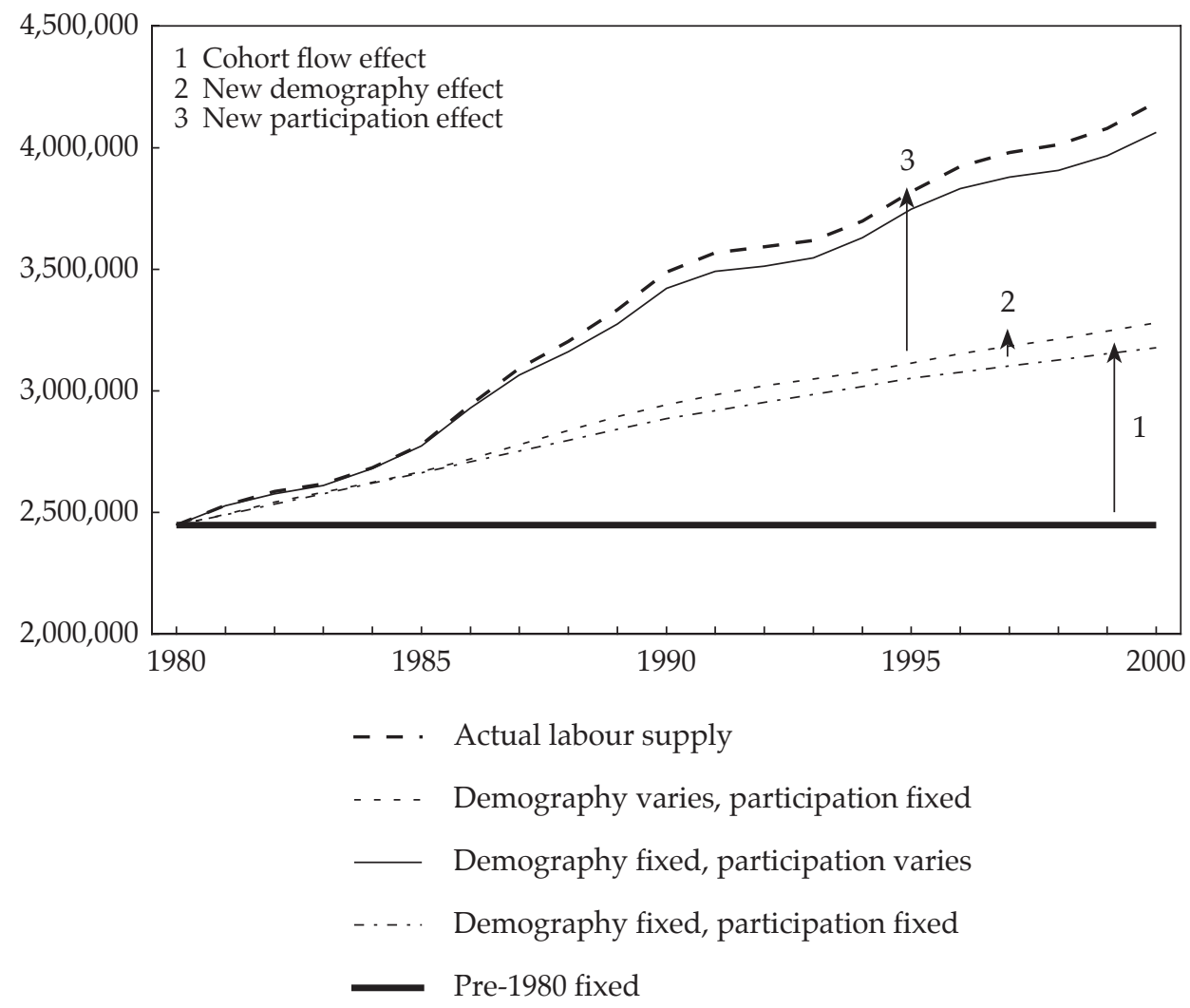




\section{Figure 2 Percentage components of labour supply change, 1980-2000}

Panel A: Components of labour supply change, males

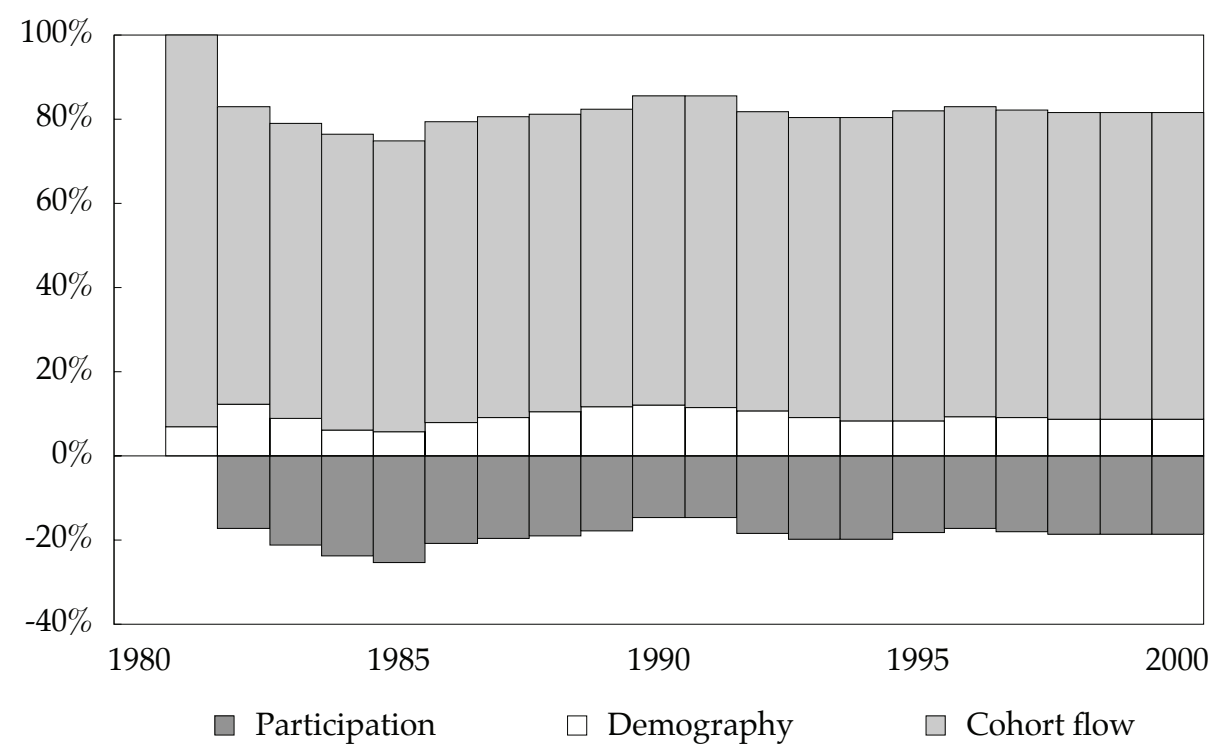

Panel B: Components of labour supply change, females

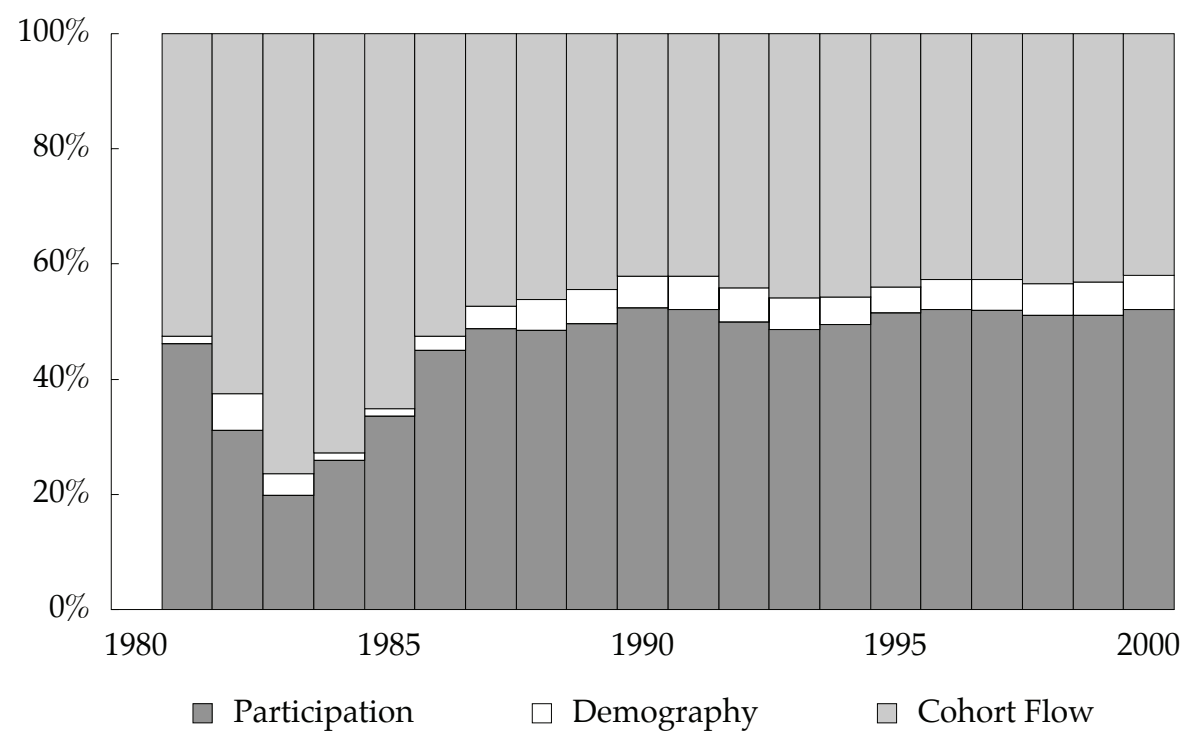


Table 3 Assumptions about Australia's demography, 2005- 2051

\begin{tabular}{|c|c|}
\hline Scenario & Demographic Parameters \\
\hline 1 Current & $\mathrm{TFR}^{\mathrm{a}}=1.8, \mathrm{ANM}^{\mathrm{b}}=110, \mathrm{e} 0 \mathrm{~m}^{\mathrm{c}}=77 \rightarrow 86.5, \mathrm{e}^{\mathrm{d}} \mathrm{f}=82.4 \rightarrow 91$ \\
\hline 2 Low fertility & TFR falls to 1.3 over 20 years \\
\hline 3 High fertility & TFR increases to 2.0 over 10 years \\
\hline 4 Low migration & ANM falls to 50,000 over 20 years \\
\hline 5 High migration & ANM increases to 190,000 over 20 years \\
\hline 6 High survival & $\mathrm{e} 0 \mathrm{~m}$ increases to 89.5 ; e0f increases to 95.1 \\
\hline
\end{tabular}

a Total fertility rate.

b Annual net migration.

c Life expectancy at age 0 for males.

d Life expectancy at age 0 for females.

mortality and migration, as distinct from structural factors determining labour force participation rates, flow through to changes in Australia's future labour supply?

To examine the different roles of structural and demographic factors in Australia's future labour supply, six separate demographic models and three separate labour force participation assumptions are used. As shown in Table 3, the base scenario (Model 1) assumes a continuation of existing fertility, existing improvements in survival and an annual net migration of 110,000 per annum. In the low-fertility scenario (Model 2), the TFR falls from 1.8 to 1.3 over a period of 20 years, and under the highfertility scenario (Model 3), the TFR increases to about 2.0 births over the next 10 years. Models 4 and 5 simulate the effect of lower and higher migration on the labour supply respectively. Under the low assumption, ANM is assumed to fall linearly to 50,000 over the next 20 years, and under the high assumption, ANM rises from 110,000 to 190,000 over the same period. Finally, the high-survival model (Model 6) simulates the effect of survival prospects increasing faster than is conventionally assumed. Research by Booth and Tickle (2003) shows that conventional assumptions about mortality used by the Australian Bureau of Statistics may reflect a significant underestimate of future survival prospects in Australia.

Figure 3 displays three different scenarios for males and females measuring structural change in the labour force, represented by labour force participation rates. The first assumption, labelled 'Current', assumes that labour force participation continues into the future at 2005 levels for males and females. The second, labelled 'Productivity Commission' refers to projections of labour force participation used by the Federal Government's Productivity Commission in much of its recent research on the economic implications of population ageing (e.g. Productivity Commission 2005). The Productivity Commission estimates were calculated using standard time-series econometric techniques and historical ABS data, and show that above age 25, female labour force participation is projected to continue increasing significantly, albeit at levels well below the levels of increase observed during the past 20 years. In contrast, for males, the Productivity Commission estimates show further declines in participation at most ages with a small increase at the higher ages. Existing government policy is directed toward the aim of higher participation for older males. The final 'High' 


\section{Figure 3 Scenarios of labour force participation rates, 2051}

Males

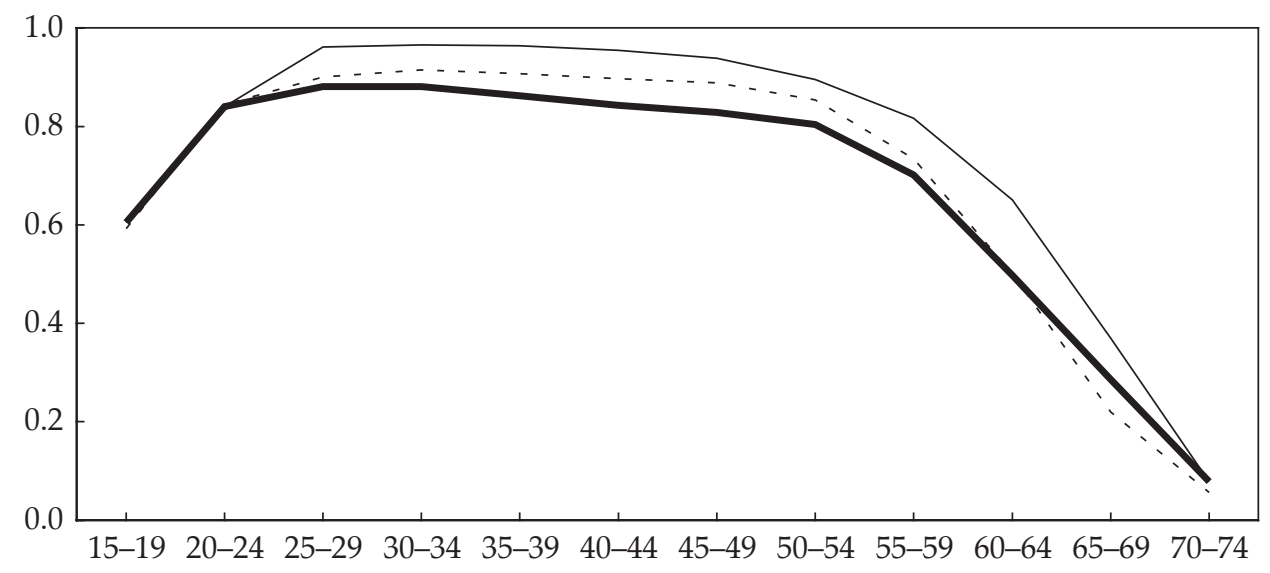

Females

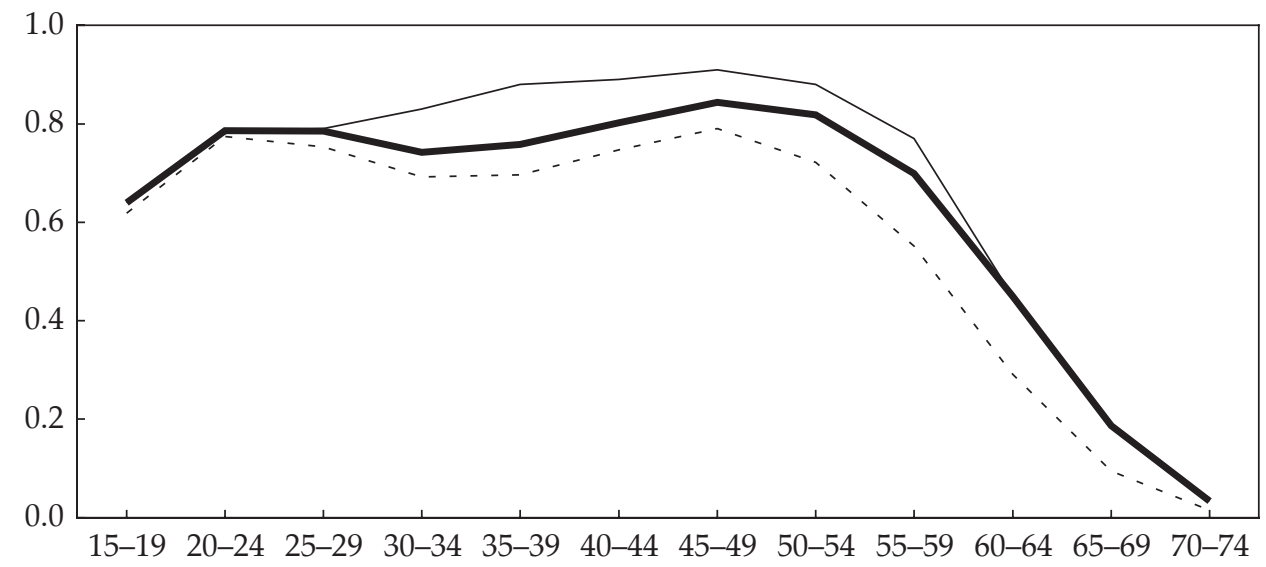

_ Productivity Commission _... Current _ High

scenario for males assumes that the age profile in the major working age groups (25-59) returns to 1980 levels but participation beyond age 60 is higher than it was in 1980. For women, we follow the high assumption of McDonald and Kippen (2001) and increase labour force participation rates for the major working age groups (2559) to the 1995 levels observed in Sweden. For the older age groups, the Productivity Commission rates are assumed.

The 'High' rates for males and females can be justified on the basis that labour demand will be high in the future and that government policies will be adjusted to facilitate participation. New superannuation arrangements are evidence of this policy direction. Already, participation rates have risen between 2000 and 2005 for men aged 50 and over and for women aged 25 and over (Table 2). Finally, Australia's 2006 participation rates at ages 35 and over, for both men and women, were well 


\section{Table 4 Selected determinants of demographic and structural factors}

Demographic Parameters

- Changes in the timing of births

- Changes in values and preferences

- Changes in the characteristics of the population

- Institutional changes (work and family, gender roles)

- Economic fluctuations

- Public debate surrounding the timing of births within the popular media, the 'waiting too long' debate.

- Supportive public policies aimed at increasing fertility, such as the new Maternity Payment.

- International competition for skilled workers.

- Social attitudes towards immigration.

- Immigration recruitment policies.
Structural Effects

- Severity, length and frequency of the business cycle

- Labour market law and legislation

- Interaction between the Australian economy and international markets

- Age at retirement

- School retention rates and participation in education

- Perceptions about the likelihood of finding work

- Family roles and responsibilities

- Structural and technological change in the economy

- Wage levels

- Attitudes towards leisure and family life relative to work

- Housing affordability

- Environmental and energy policies.

Sources: ABS 1999; Temple and McDonald 2006.

below those of New Zealand in 2005. It seems extraordinary in these circumstances to project that male participation rates in the main working ages will actually fall in the future. Using men aged 55-59 as an example, the actual participation rate rose from 70.2 per cent in 2001 to 77.5 per cent in 2006, yet the Commission takes 73.9 per cent as its starting point for projections and then moves the rate downwards over time to 73.3 per cent. The rate for 55-59-year-old New Zealand men in 2005 was 86 per cent and this is the age group that will be most affected by recent changes in the taxation of superannuation benefits.

In simulating these alternative labour supply futures, it is important to recognize that a variety of factors will affect the underlying demographic parameters as well as possible labour force participation rates. For example, the future timing of births has important implications for the level of fertility, and future labour market law and legislation will clearly influence labour force participation rates (Table 4).

\section{Projected labour supply size}

Table 5 displays results of the projections of labour supply under each of 18 models for males and females at 20-year intervals: 2006, 2026 and 2046. Under current demographic and structural assumptions (base projection), male labour supply is projected to grow to about 6.5 million over the next 20 years, and to about 5.3 million for females over the same period. Over this 20-year period, this presents a 14 per cent increase in male labour supply and an 11 per cent increase in female labour supply. Importantly, the growth rates slow considerably in the second 20 years of the projection period. Between 2026 and 2046, the base projections show a 6.7 per cent growth 
rate in male labour supply and a 5.2 per cent growth in the female labour supply. Over the full 40 -year period, male labour supply grows by 22 per cent and female supply by 17 per cent. This 40 -year growth is considerably slower than the 20-year rates observed for the period 1980-2000 that were 26 per cent and 71 per cent for males and females respectively.

There is considerable variation in the projected labour supply according to the assumptions about demography and participation that are used. Across the 18 projections, by 2026, the projected labour supply ranges from 6.25 million to 7.3 million for males and between 5.0 and 6.3 million for females. By the late 2020s, the labour supply growth actually turns negative for a number of the low migration and low fertility models.

\section{Relative roles of demographic and structural factors}

Figure 4 displays the relative effects of demography and structural factors upon labour supply, with each other factor and cohort flow held constant. Holding structural effects constant, the high-migration scenario has the strongest effect on labour supply, a 14 per cent increase by 2051, followed by the high-fertility model, five per cent. As expected, the high survival model has a negligible effect on labour supply, as increases in longevity realize gains only in old-old ages. Both the low-migration and low-fertility models reduce the labour supply by about 10 percentage points to 2051. It is important to recognize the non-linear effects, particularly for changes in fertility. This is a function of two factors: first, the assumptions used about the timing of fertility decline, but more importantly, secondly, the time it takes from birth to gain an education or training before entry into the labour force. These general patterns are replicated for both males and females.

Holding the demographic factors constant (including cohort flow), changing participation rates also have a strong effect upon future labour supply (Panel C). Compared to existing 2005 labour force participation rates, a change to the forecast Productivity Commission rates would see a 10 per cent increase in female labour supply and a three per cent decrease in male labour supply. In the high scenario, female labour supply would increase by almost 20 per cent by 2031, and that of males by about 10 per cent.

\section{Interaction between demographic and structural factors}

Of course, the decomposition between demographic and structural factors is not straightforward. For example, there are interaction effects operating between increased labour force participation and increased fertility. An increase in fertility increases the working-age population and an increase in participation increases the labour supply regardless of any changes in demography. Moreover, the relationship between demographic and structural determinants of labour supply can also be conceivably thought of as endogenous, as depicted in Figure 5. For example, demographers conceive of education status as a proximate determinant of fertility. Similarly, education is a very good determinant of labour supply. In this respect, the decision that a household makes with respect to child rearing and labour force participation is jointly determined, in this example, by the same underlying determinant. The results in this study have not sought to model the exact elasticities, or degree of endogeneity between these parameters, but this important area of research is currently receiving attention by the authors. 


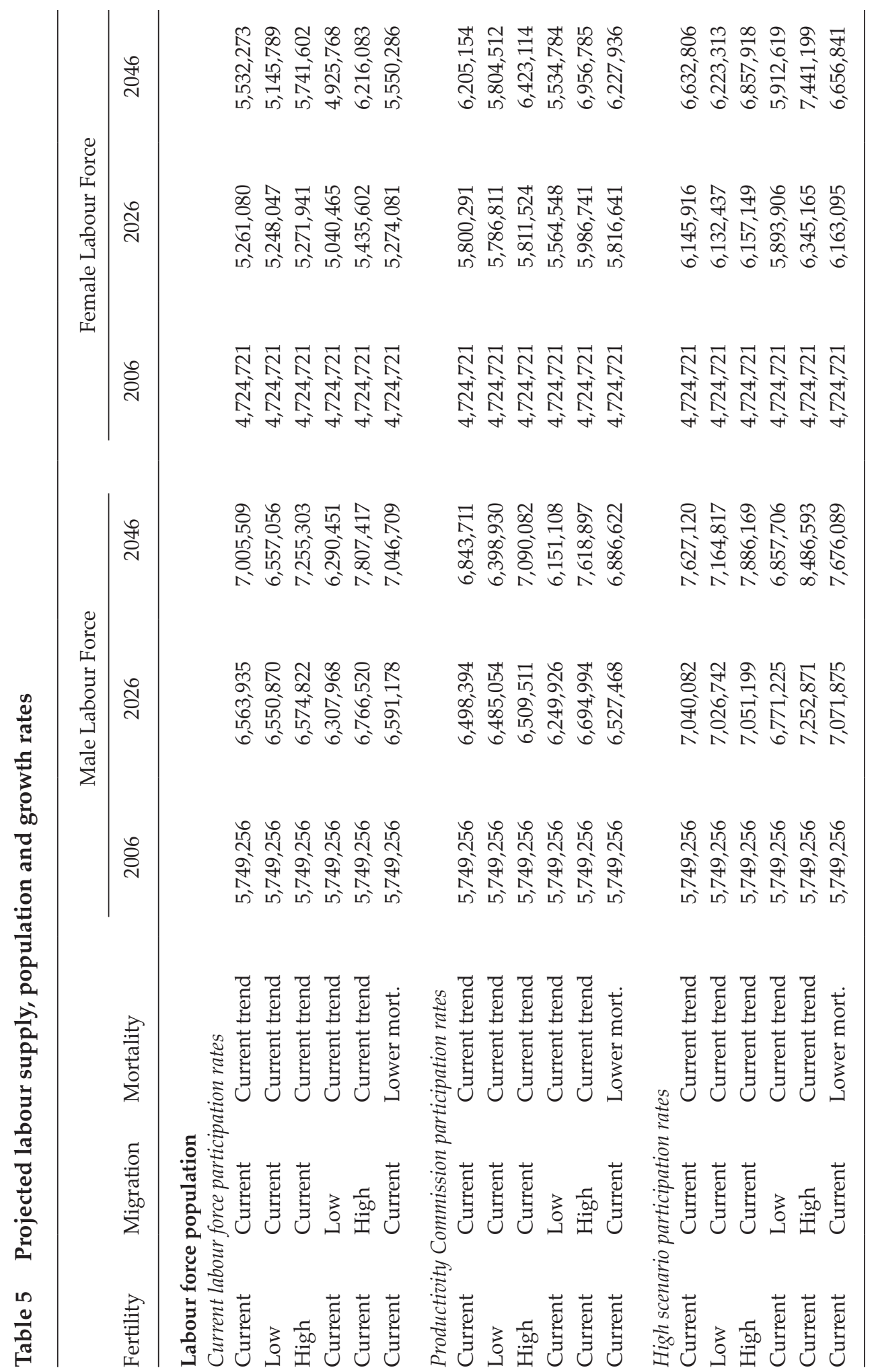




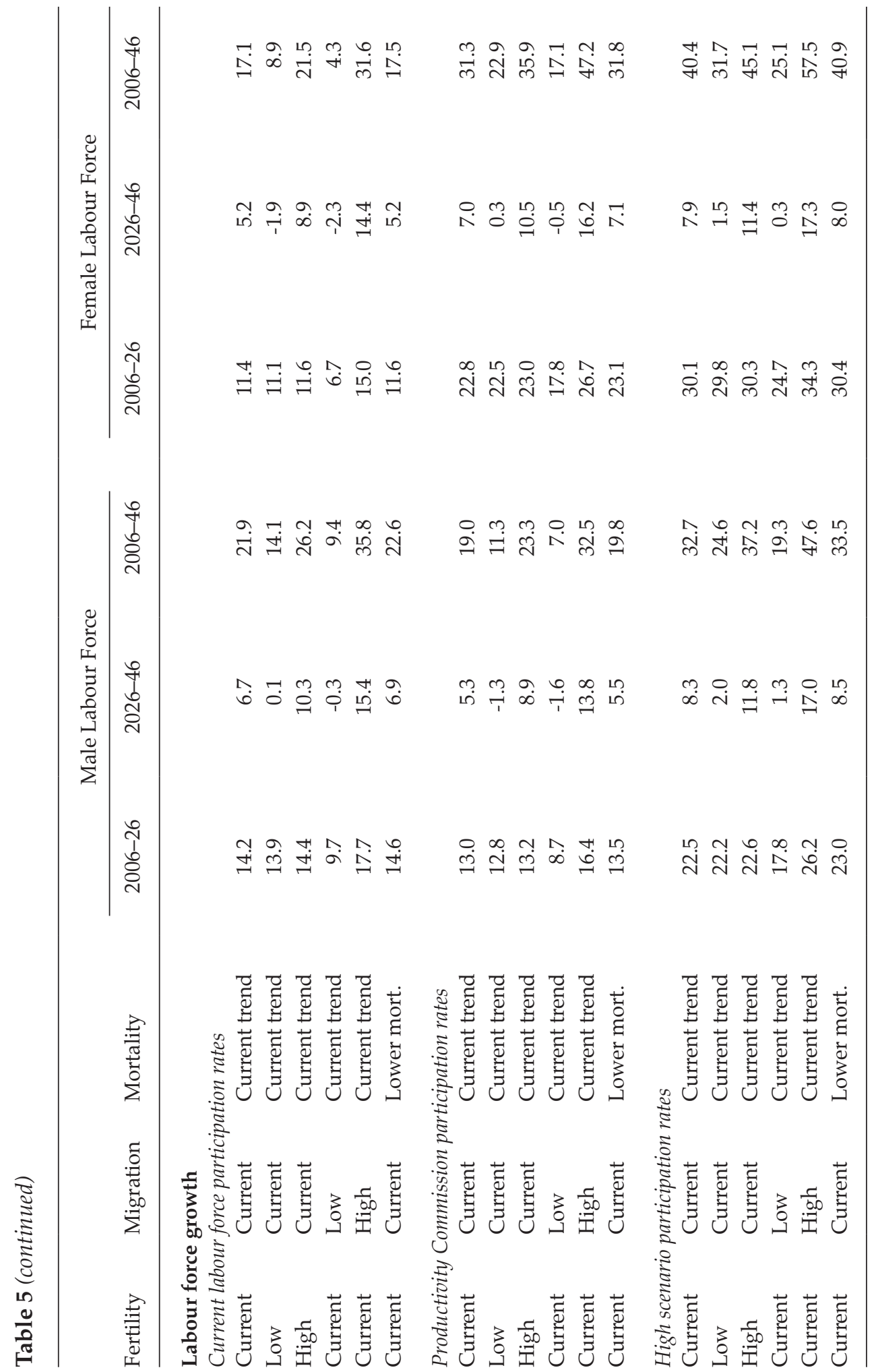


Figure 4 Percentage change in labour supply, by scenario

Panel A: Demographic effects, males

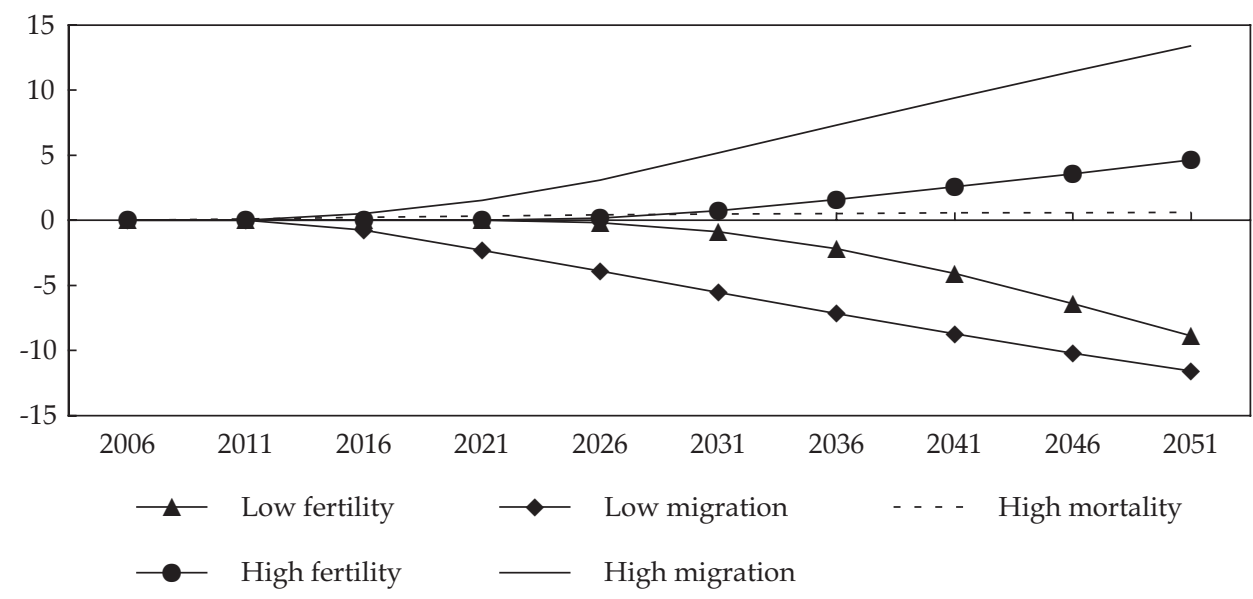

Panel B: Demographic effects, females

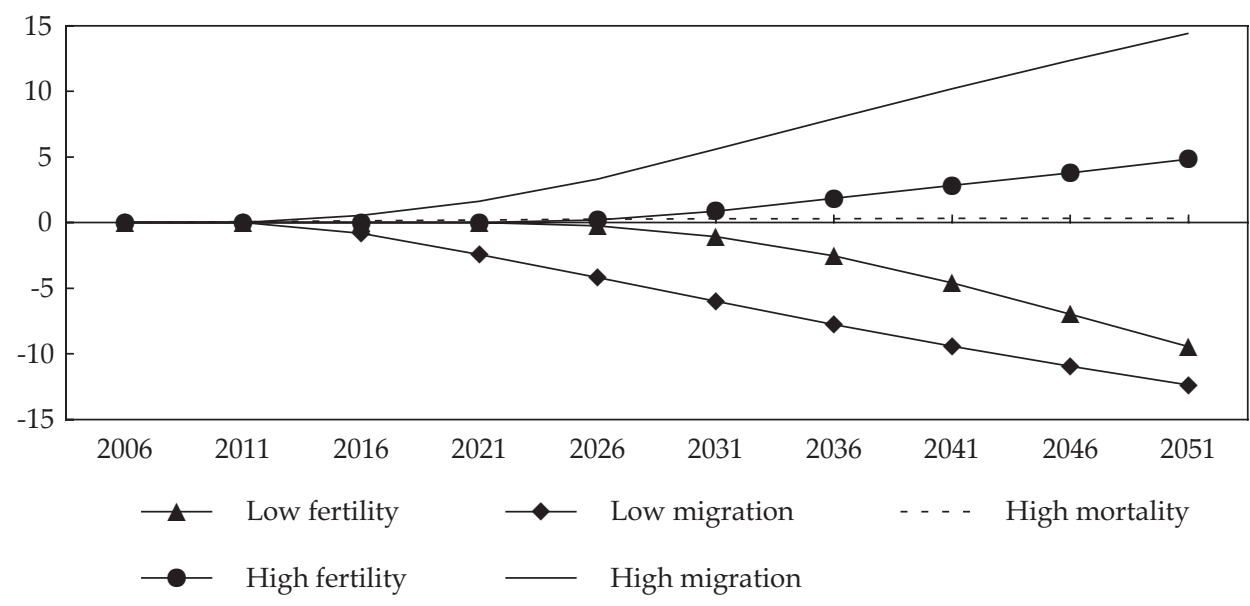

Panel C: Structural effects, males and females

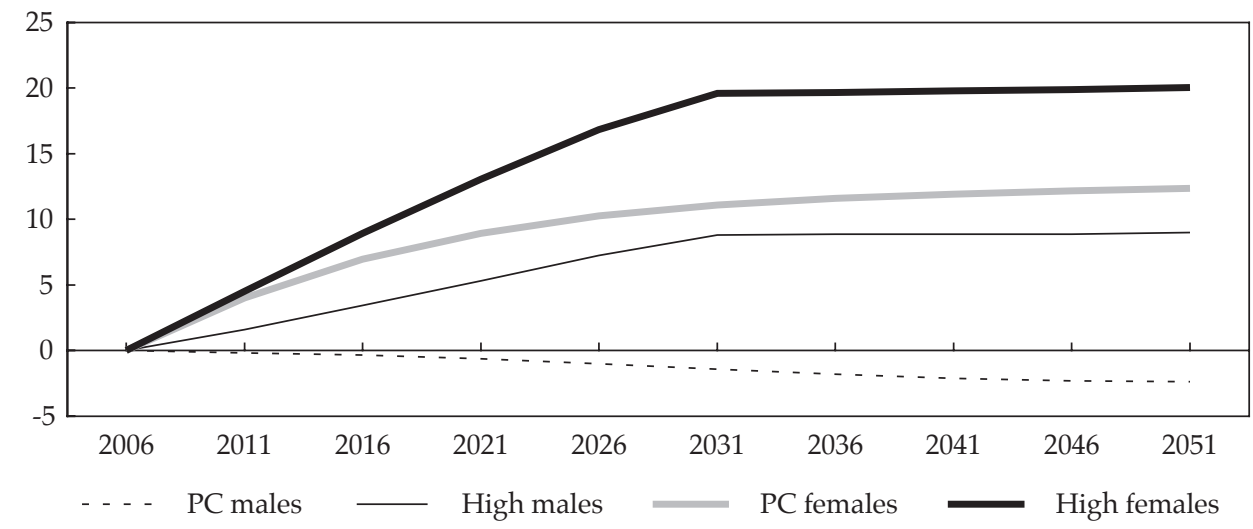




\section{Figure 5 Endogeneity between demographic, structural factors and labour supply}

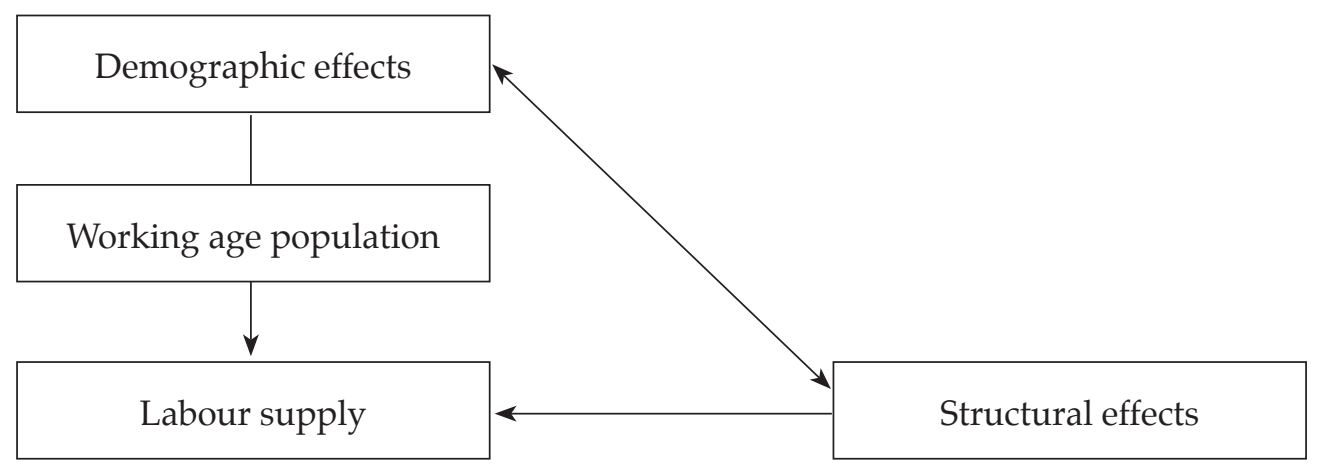

These effects operating between the structural and demographic determinants of labour supply raise the question of the ability of one to offset the other. For example, if the government is successful in implementing policies to increase labour force participation in retirement, perhaps the gains in participation could be offset by a decrease in fertility or a decline in net migration, due to either an acceleration of younger people leaving Australia, or a lack of appropriately skilled labour in the international labour market.

The results in Figure 6 show the effect of an increase in participation and a decrease in fertility on labour supply. The model marked 'FDFR' (Fixed Demography, Fixed Rate) is the base model assuming that participation and demography remained fixed at their 2005 levels; 'FDVR' (Fixed Demography, Varied Rate) fixes demography, but increases participation; 'VDFR' (Varied Demography, Fixed Participation) decreases fertility to 1.3 births, but increases participation; and 'VDVR' increases participation and decreases fertility simultaneously. As shown in Figure 6, the effect of a decrease in fertility can indeed offset increases in participation over the longer term. In the shorter term, the labour supply continues to grow under increased participation, as the labour supply does not call upon workers born in 2006 until about 20 years later. At this point, labour supply growth turns negative and by 2051 completely offsets the gains in labour supply attributable to increased participation. As shown in Panel B of Figure 6, the relative contribution of cohort flow falls over the projection period, accentuating the downward effect of low fertility on labour supply.

\section{Implications for age structure of the labour supply}

It is not only low labour-supply growth that presents problematic policy issues, but also the composition of the labour supply. More specifically, the age composition of the labour supply and the timing of labour market entries and exits have important implications for sustaining labour supply growth and boosting labour productivity (McDonald and Temple 2006). Figure 7 displays labour supply population pyramids under each of the demographic assumptions. Clearly, low fertility and low migration exacerbate the ageing of the labour supply. In contrast, both high migration and high fertility models induce a reduction in the age of the labour force when compared to the current-trend demography. 
Figure 6 Can an increase in labour force participation be offset by a decline in fertility?
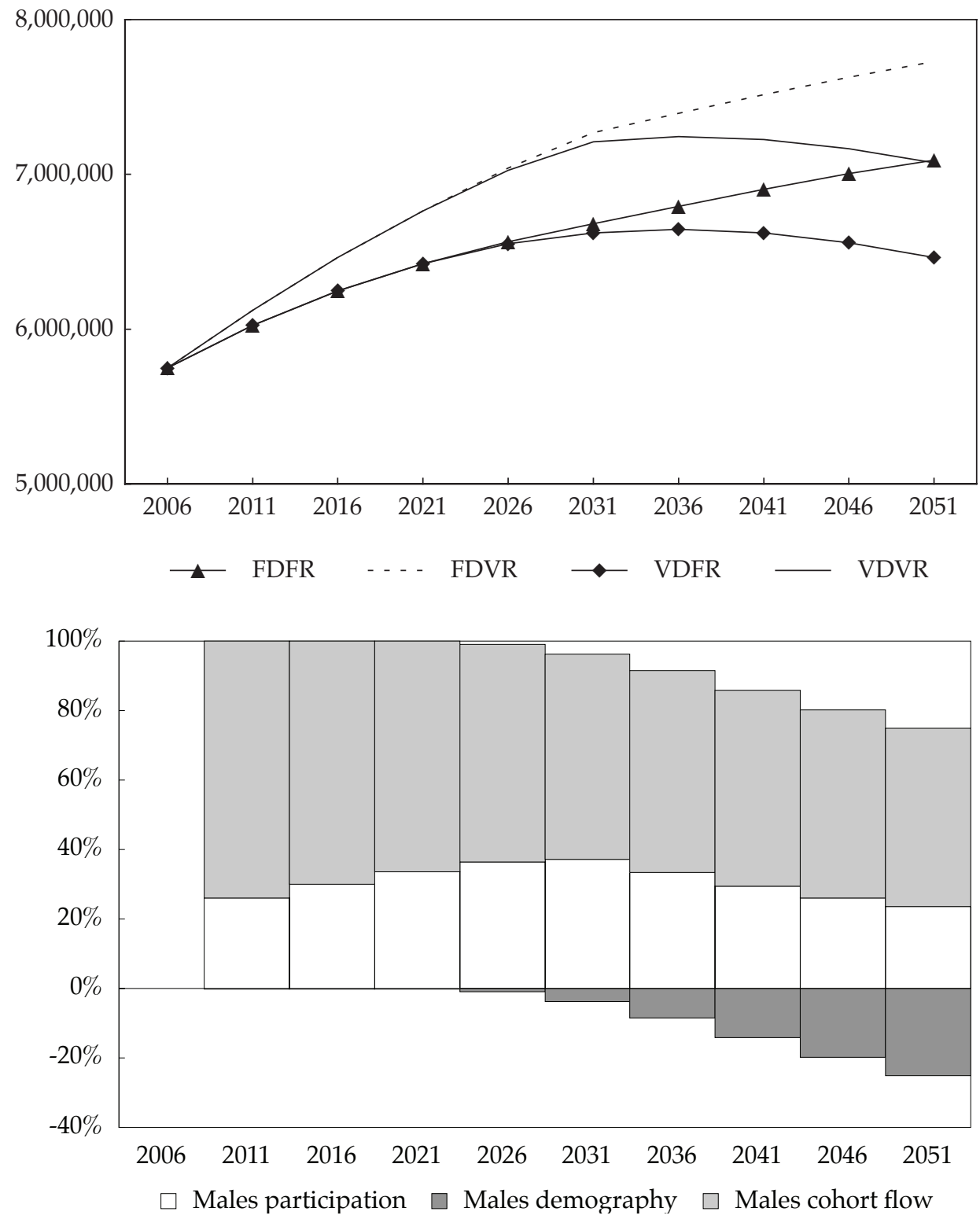

These differing demographic assumptions also alter the timing and composition of labour market entries and exits, as measured by the Labour Market Entry Exit Ratio, LMEER (Figure 8). This measures the number of people entering the labour market, defined as those in the labour market aged between 15 and 24, as a ratio of the number of people leaving the labour market, defined as those in the labour market aged 55-64. An LMEER of 1 indicates that the number of people of labour market entry age matches the number of people of labour market exit age. Below 1, exits 
Figure 7 Age distribution of the labour supply, by demographic scenario, 2006 (shaded) and 2051

Current

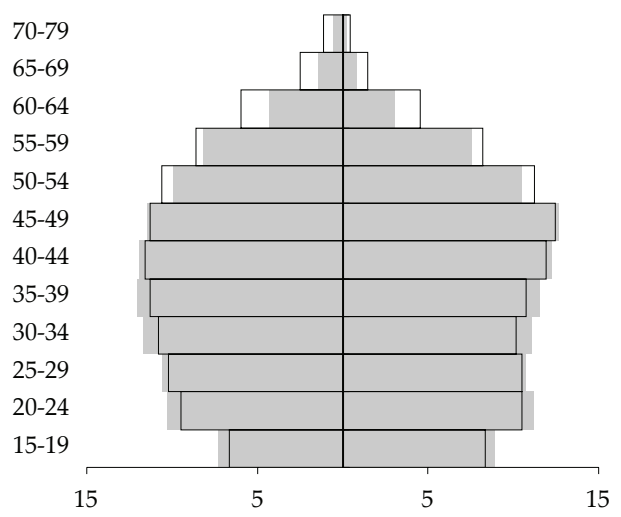

High fertility

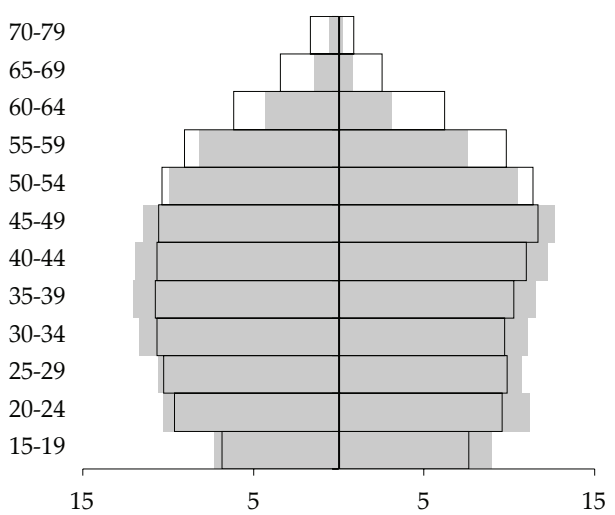

High migration

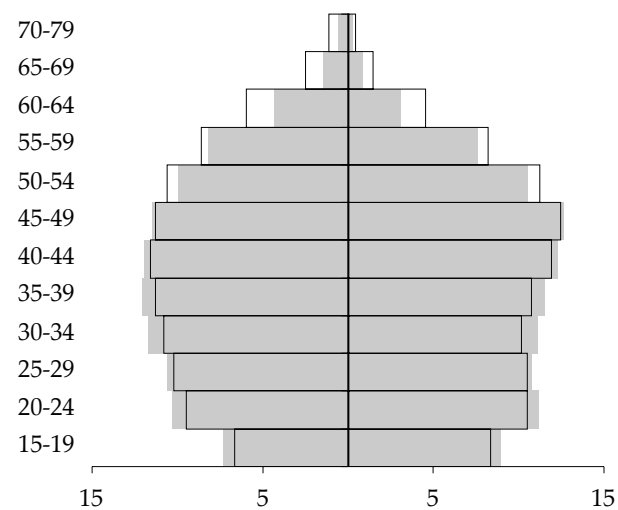

Low fertility

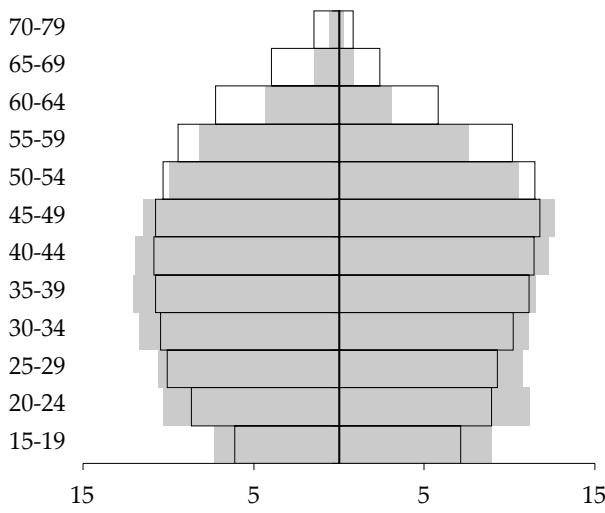

Low migration

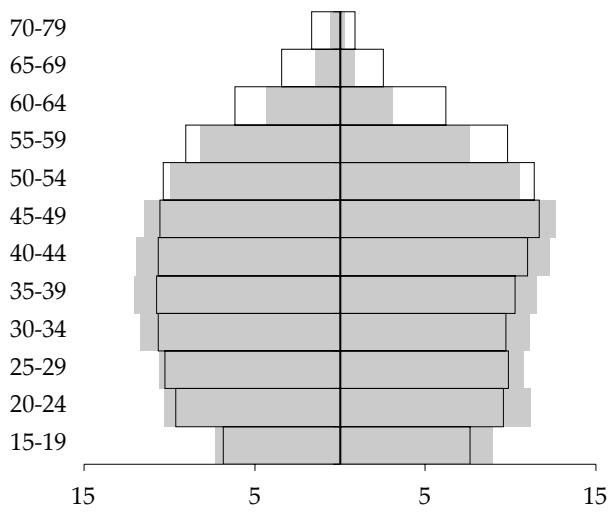

High survival

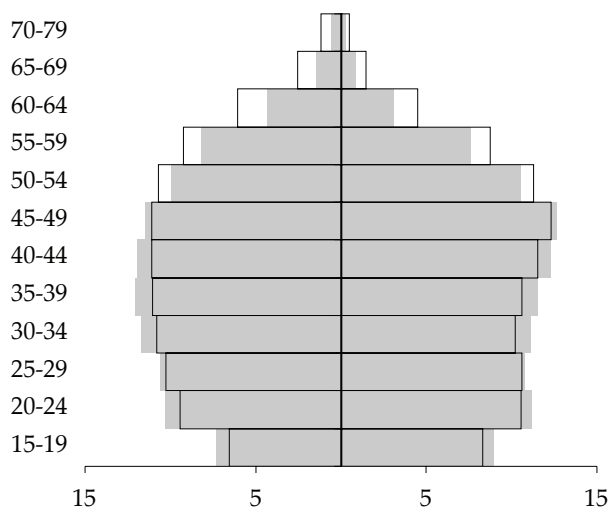


Figure 8 Labour Market Entry Exit Ratio (LMEER), by demographic and structural scenario, 2006-2051

Demography scenario LMEER, males

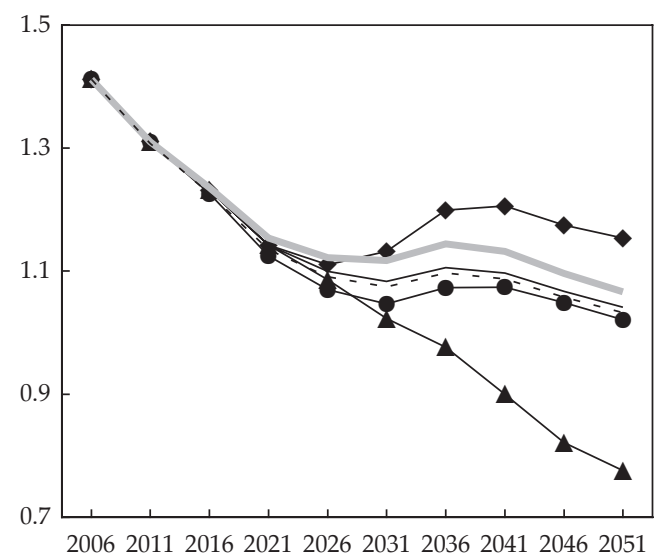

Demography scenario LMEER, females

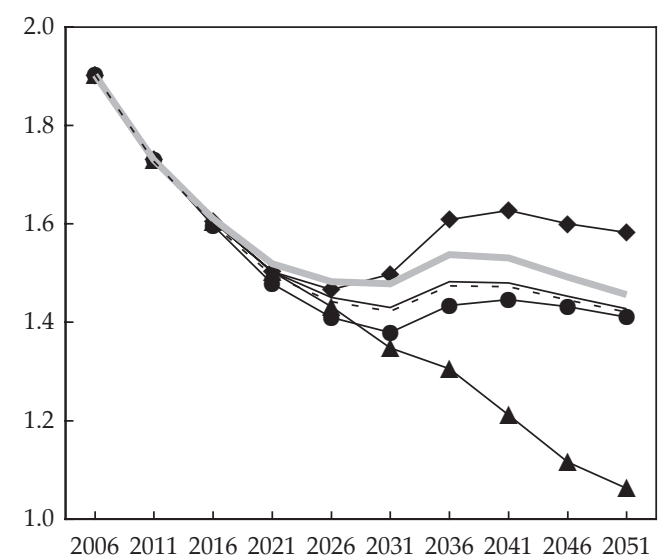

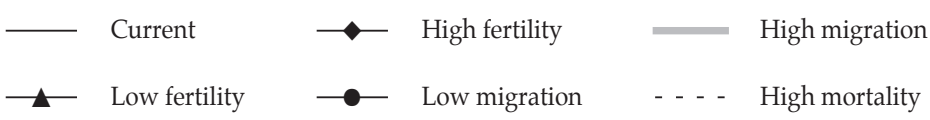

Structural scenario LMEER, males

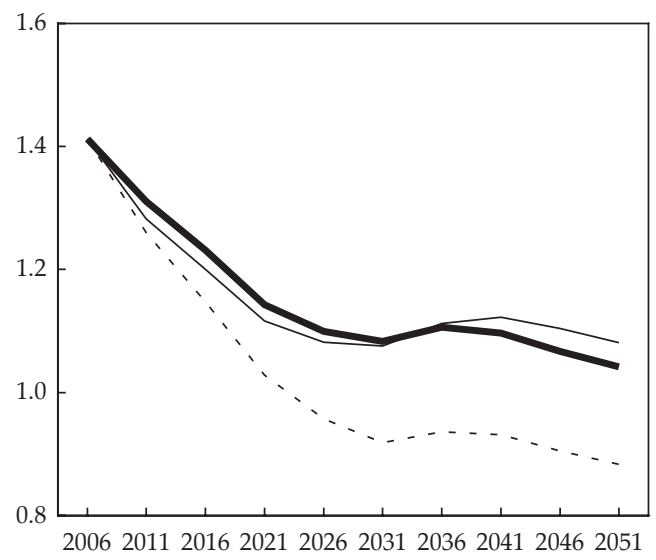

Structural scenario LMEER, females

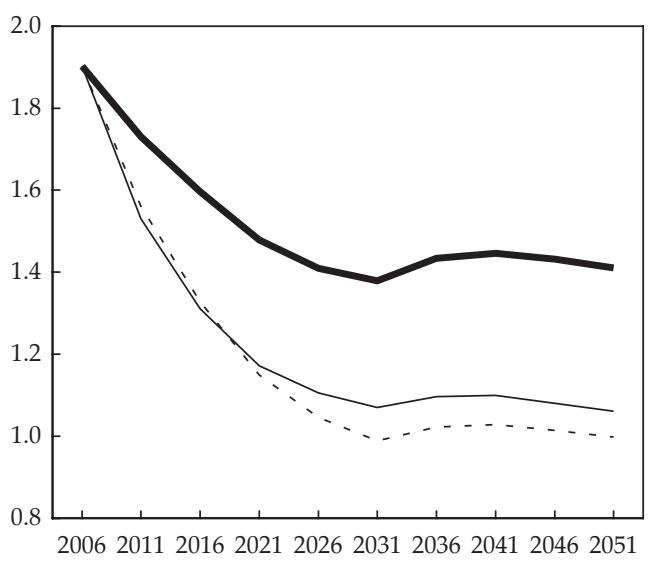

- - - High $\longrightarrow$ PC $\longrightarrow$ Current

outnumber entries, and the converse is true for values above the line. In 2006, the base year, there were 1.4 males and 1.9 females of labour market entry age to every person of labour market exit age. Assuming current demographic patterns, by 2051 labour market exits outnumber entries and by 2026, there are 0.91 entries for every one exit.

The timing of potential labour market supply constraints differs considerably between the demographic models. With low fertility, there is an excess of labour 
market exits much earlier than in all other models and the rate of the reduction of labour market entries is far greater after 2026. Importantly, in the high-fertility and high-migration model, the excess of exits over entries is delayed much further when compared to the current-trend demography model.

Moreover, the alternative age-sex specific participation scenarios also considerably affect the timing of labour market entries and exits. For males, the current and Productivity Commission assumptions yield similar LMEER: falling from 1.4 entries in 2006 to around 1.1 in 2030 and beyond. For the high scenario assumptions and the high and Productivity Commission scenarios for females, the LMEER falls far more quickly. For example, for females under the high assumptions, the ratio of entries to exits falls from 1.9 in 2006 to 1.0 by 2030. These results may seem contradictory: higher participation exacerbating the timing of labour market exits. However, this is due to the higher participation scenarios increasing participation at higher ages. This once more underscores the importance of maintaining fertility to ensure a continued supply of younger workers.

\section{Discussion and conclusion}

From 1980 to 2005, Australia's labour supply grew by almost 60 per cent and its economy was geared to a rapid increase in labour supply, particularly an increase in younger skilled workers. Two of the drivers of this growth in labour supply, the full entry of the baby-boom generation into the labour force and very large increase in female labour force participation rates, will not be part of future labour supply change. Even with very high levels of migration by historical standards and very high labour force participation rates by recent standards, in the next 20 years, Australia's labour supply would grow by just 26 per cent for men and 34 per cent for women, that is, at about half the level of growth of the past 20 years. A continuation of current trends would see labour supply grow in the next 20 years by only 14 per cent for men and 11 per cent for women. These two scenarios probably cover the likely range of possibilities and their midpoint implies a growth of total labour supply of around 20 per cent. Thus the Australian economy will need to gear down to a much slower growth in labour supply at the same time as the population begins to age rapidly. This is a certainty. If the growth of labour supply is at the low end of these projections, supply will fall in the younger age-groups of the labour force. At a time when technological change will be very rapid and Australia will need to be shifting to new energy sources and new forms of energy-efficient infrastructure, a fairly substantial fall in the numbers of young skilled workers seems a risky situation. Indeed, young workers are essential in developing and implementing new technologies in Australia's future labour market (McDonald and Temple 2006).

In the 20-year period from 2026 to 2046, labour supply growth will be even slower. Under current conditions, labour supply growth in the second 20-year period from now would be just six per cent and this is the period in which the ageing of the population will be greatest. The high labour force participation scenario would be largely ineffective in this second period because its goals would have been achieved in the first 20-year period. Thus, growth in the second period is driven almost entirely by population components over the full 40-year period, fertility and immigration. This is where the mistake is made that the ' $\mathrm{P}$ for population' component is not an important policy lever. While differences in fertility between 2006 and 2026 make no 
difference to labour supply in that period, they have a very large effect in the second 20-year period from 2026 to 2046. The message from this is: do not ignore the P for population.

All of the above ignores labour demand and this is a serious omission. First, demographic change is not independent of labour demand. Increases in skilled migration or substantial increases in fertility would increase labour demand. The degree to which the increase in labour supply caused by increases in fertility or migration would be offset by an increase in labour demand is a consideration for further analysis. Secondly, our view is that labour demand is likely to be very strong in Australia, independent of shifts in fertility or migration, in the future because (1) living standards will rise considerably creating new demand for service workers; (2) the ageing of the population will also create new demand for service workers; and (3) there will be very heavy labour demand arising from the need to invest in new physical infrastructure. Infrastructure development has been neglected to a large extent in Australia since the 1970s. Massive new investment is required to deal with environmental degradation including greenhouse gas emissions, water supply, the transformation from an oil-based economy, and transport and communications inefficiencies. The inevitable changes in the 'way we live our lives' because of global warming, changes in energy forms, new approaches to water supply and sewerage, transport and communications will demand highly skilled technological workers. The demand for Australian export products, especially its minerals, will almost certainly rise. However, these views about future labour demand are not expressed in quantified terms because, at present, we do not have reliable ways of estimating long-term labour demand. Any estimate of long-term labour demand will have a wide range of variability; however, for many occupations, especially service occupations broadly-defined, long-term estimates are possible and would provide a better planning perspective than no estimates. Moreover, productivity improvements have also not been included in this discussion of labour demand. Obviously, the timing of labour supply constraints must take account of productivity improvements and labour demand. In a subsequent paper, we intend to decompose the role of productivity improvements in the output of labour supply.

In summary, this paper has examined the role of structural and demographic factors in Australia's past and future labour supply. Results indicate that a substantial proportion of the growth in male and female labour supply in the past and future is a result of cohort flow. This is consistent with Costello's mantra that 'Demography is destiny'. However, focusing upon cohort flow only ignores the important gains that can be made in labour supply through maintaining or increasing fertility and increasing targeted migration strategies. These aspects of demographic change are certainly not written, and much can be done to plan for future labour supply contingent upon appropriate policies aimed at maintaining fertility and increasing targeted skilled migration. Increasing labour supply through improved participation of older persons alone does little to combat the ageing of the labour supply itself.

\section{Acknowledgments}

The original manuscript was improved by comments made by two anonymous reviewers. The authors benefited from the research assistance of Anna Reidy. 


\section{References}

Australian Bureau of Statistics (ABS). 1999. Labour Force Projections, Australia 1999-2016. Cat. No. 6260.0. Canberra.

Booth, H. and L. Tickle. 2003. The future aged: new projections of Australia's elderly population. Australasian Journal on Ageing 22(4): 196-202.

Boxall, P. 2006. Work and welfare: getting the balance right. Paper presented to ANU Demography Australian Social and Economic Policy Public Lecture Series, Canberra. 16 May.

Costello, P. 2002. Intergenerational Report 2002-03. Budget Paper No.5. Canberra: Department of Treasury.

Costello, P. 2004. Interview with Alexandra Kirk, ABC AM. Transcript, The Hon Peter Costello, MP. <http:/ / www.treasurer.gov.au/tsr/content/transcripts/2004/165.asp> Accessed 28 March 2007.

Dowrick, S. and P. McDonald. 2002. Comments on Intergenerational Report, 2002-03. Australian National University, Canberra. < http://dspace.anu.edu.au/handle/1885/40240> Accessed 28 March 2007.

McDonald, P. and R. Kippen. 2001. Labour supply prospects in 16 developed countries, 2000 2050. Population and Development Review 27(1): 1-32.

McDonald, P. and J. Temple. 2006. Immigration and the Supply of Complex Problem Solvers in the Australian Economy. Canberra: Department of Immigration and Multicultural and Indigenous Affairs.

Mitchell, W. and W. Mosler. 2003. The Intergenerational Report: myths and solutions. Working Paper No. 03-10. Newcastle: Centre of Full Employment and Equity, University of Newcastle.

Productivity Commission. 2005. Economic Implications of an Ageing Australia. Canberra.

Temple, J. and P. McDonald. 2006. The Australian population: a background primer. Pp. 61-89 in J. Reich et al. (eds), Defence Personnel Environment Scan 2025. Canberra: Department of Defence. 